\title{
Synthesis and catalytic activity of metallo-organic complexes bearing 5-amino 2-ethylpyridine -2-carboximidate
}

\author{
LUO MEI*, XU JIA and ZHANG JING CHENG \\ Department of Chemical Engineering, Hefei University of Technology, Hefei, 230009, China \\ e-mail: luomei@pku.edu.cn
}

MS received 9 March 2016; revised 16 April 2016; accepted 24 April 2016

\begin{abstract}
A series of copper, cobalt, nickel and manganese complexes were synthesized and characterized. Reaction of 5-amino-2-cyanopyridine with $\mathrm{MCl}_{2} \cdot \mathrm{xH}_{2} \mathrm{O}\left(\mathrm{M}: \mathrm{Cu}^{2+}, \mathrm{Co}^{2+}, \mathrm{Ni}^{2+}, \mathrm{Mn}^{2+}\right)$ in anhydrous ethanol resulted in the formation of four complexes $\left[\mathrm{NH}_{2} \mathrm{EtPyCuCl} 2\left(\mathrm{CH}_{3} \mathrm{OH}\right)\right] \cdot \mathrm{H}_{2} \mathrm{O} \mathrm{1}$, $\left[\left(\mathrm{NH}_{2} \mathrm{EtPyHCl}\right)_{3} \mathrm{Co}\right]$ $(\mathrm{Cl})_{3} .3 \mathrm{H}_{2} \mathrm{O} 2$ 2, $\left[\left(\mathrm{NH}_{2} \mathrm{EtPy}\right)_{2} 2\left(\mathrm{H}_{2} \mathrm{O}\right) \mathrm{Ni}\right]\left(\mathrm{Cl}_{2}\right)$ 3, and $\left[\left(\mathrm{NH}_{2} \mathrm{EtPy}\right)_{2} 2\left(\mathrm{H}_{2} \mathrm{O}\right) \mathrm{Mn}\right]\left(\mathrm{Cl}_{2}\right) 4\left[\mathrm{NH}_{2} \mathrm{EtPy}=5\right.$-amino-Oethylpyridine-2-carboximidate], respectively. The structures of these compounds were determined by X-ray diffraction, NMR and IR spectroscopy, and elemental analysis. Each complex was then used as a catalyst in the Henry reaction, and its catalytic activity was determined by ${ }^{1} \mathrm{H}$ NMR. Good catalytic effects were achieved $(69-87 \%)$.
\end{abstract}

Keywords. 5-amino-2-cyanopyridine; metal complex; $\mathrm{NH}_{2} \mathrm{EtPy}$; the Henry reaction.

\section{Introduction}

Copper, cobalt, nickel and manganese complexes involving carboximidate have drawn much attention in the fields of organic synthesis and pharmaceuticals. ${ }^{1-7}$ This is due to the importance of the carboximide ester structural unit as an intermediate or ligand in these fields. For example, this unit can be used as the catalyst for the atom transfer radical polymerization of methyl methacrylate, ${ }^{8}$ or as a new class of chiral Lewis acid catalysts for highly enantioselective hetero-DielsAlder reactions. ${ }^{9}$ The crystal structure of a similar complex involving O-methylpyridine-2-carboximidate was reported in 1995 by M. Jamnicky. ${ }^{10}$ Inspired by that pioneering work, herein, we describe for the first time the synthesis and characterization of some copper(II), cobalt(II), nickel(II) and manganese(II) complexes that contain 5-amino-2-cyanopyridine. The complexes were formed in systems containing 5-amino-2-cyanopyridine, metal(II) salts, and anhydrous ethanol and without any catalyst. Additionally, we also used these complexes to catalyze the Henry reaction and achieved good catalytic effects.

\section{Experimental}

5-amino-2-cyanopyridine, $\mathrm{CuCl}_{2} \cdot 2 \mathrm{H}_{2} \mathrm{O}, \mathrm{CoCl}_{2} \cdot 6 \mathrm{H}_{2} \mathrm{O}$, $\mathrm{NiCl}_{2} \cdot 6 \mathrm{H}_{2} \mathrm{O}$ and $\mathrm{MnCl}_{2} \cdot 4 \mathrm{H}_{2} \mathrm{O}$ were purchased from

\footnotetext{
*For correspondence
}

Acros, Aldrich, Fluka, and Sinopharm Chemical Reagent Company, ${ }^{1} \mathrm{H}$ NMR spectra were obtained using a Bruker AM-300 spectrometer. The following abbreviations were used to designate chemical shift mutiplicities: $\mathrm{s}=$ singlet, $\mathrm{d}=$ doublet, $\mathrm{t}=$ triplet, $\mathrm{m}=$ multiplet. Infrared spectra were recorded on a Mattson Galaxy Series FTIR 3000 spectrometer and peaks are reported in $\mathrm{cm}^{-1}$. Elemental analysis was performed on VARIO ELIII elemental analyzer. Crystal structure was determined by Gemini S Ultra diffractometer.

\subsection{Structure determination}

The green crystal of compound $\mathbf{1}$ with approximate dimensions of $0.230 \times 0.180 \times 0.110 \mathrm{~mm}$ was selected for the data collection on a 'graphite' diffractometer with mirror monochromated $\left(\mathrm{Mo} K_{\alpha}\right.$ radiation, $\lambda=$ $0.71073 \AA$ Á). A total of 8273 reflections were collected in a range of $2.094<\theta<26.000^{\circ}$ by using " $\omega$ and $\Phi$ " scan techniques at 293(2) K, $M=349.69$, Monoclinic,

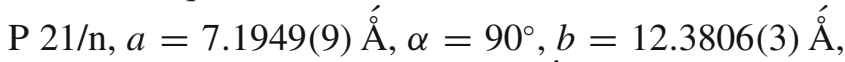
$\beta=93.630(3)^{\circ}, c=15.758(2) \AA ̊ \AA, \gamma=90^{\circ}, V=$ $1400.9(3) \AA^{3}, Z=4, D_{\text {calc. }}=1.658 \mathrm{Mg} / \mathrm{m}^{3}$, and the final $R$ factor was $R_{1}=0.0290,2754$ reflections were observed with $I_{0}>2 \sigma\left(I_{0}\right), \mathrm{R}_{\omega}=0.0769$ for all data. The structure was solved by full-matrix least-squares on $F^{2}$ using the SHELXTL PROGRAM. ${ }^{9}$

The purple red crystal of compound 2 with approximate dimensions of $0.180 \times 0.150 \times 0.150 \mathrm{~mm}$ was selected for the data collection. A total of 26140 
reflections were collected in a range of $4.270<$ $\theta<65.479^{\circ}$ by using " $\omega$ and $\Phi$ " scan techniques at 296(2) $\mathrm{K}, M=735.96$, Monoclinic, P 21/n, $a=$ 13.5023(12) $\AA$ ', $\alpha=90^{\circ}, b=16.0669$ (15) $\AA$, $\beta=90^{\circ}$, $c=16.1341(14) \AA ̊ \AA, \gamma=90^{\circ}, V=3500.1(5) \AA^{3}, Z=$ $4, D_{\text {calc. }}=1.397 \mathrm{Mg} / \mathrm{m}^{3}$, and the final $R$ factor was $R_{1}=0.0706,5372$ reflections were observed with $I_{0}>2 \sigma\left(I_{0}\right), \mathrm{R}_{\omega}=0.1665$ for all data. The structure was solved by full-matrix least-squares on $F^{2}$ using the SHELXTL PROGRAM. ${ }^{11}$

The light green crystal of compound $\mathbf{3}$ with approximate dimensions of $0.30 \times 0.280 \times 0.250 \mathrm{~mm}$ was selected for the data collection. A total of 13927 reflections were collected in a range of $1.841<\theta<30.898^{\circ}$ by using " $\omega$ and $\Phi$ " scan techniques at $296.15 \mathrm{~K}$, $M=496.04$, Monoclinic, C 1 2/c 1, $a=17.460(4) \AA ̊$,

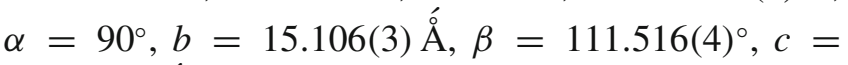

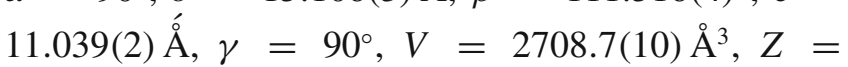
$4, D_{\text {calc. }}=1.216 \mathrm{Mg} / \mathrm{m}^{3}$ and the final $R$ factor was $R_{1}=0.0475,4242$ reflections were observed with $I_{0}>2 \sigma\left(I_{0}\right), \mathrm{R}_{\omega}=0.1122$ for all data. The structure was solved by full-matrix least-squares on $F^{2}$ using the SHELXTL PROGRAM. ${ }^{11}$
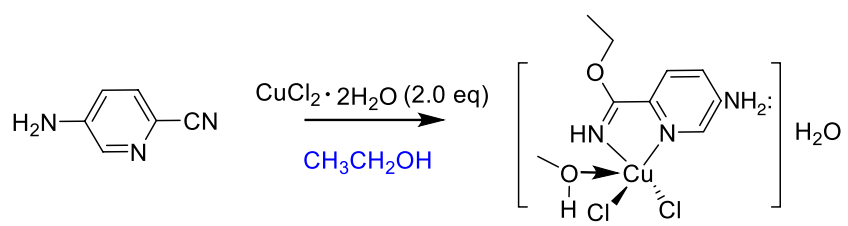

Scheme 1. The synthetic route for complex 1. Reagents and conditions: ethanol, $80-90^{\circ} \mathrm{C}, 48 \mathrm{~h}$.
The yellow crystal of compound 4 with approximate dimensions of $0.170 \times 0.150 \times 0.110 \mathrm{~mm}$ was selected for the data collection. A total of 7967 reflections were collected in a range of $2.330<\theta<25.492^{\circ}$ by using " $\omega$ and $\Phi$ " scan techniques at 293(2) K, $M=545.31$, Monoclinic, C 2/c, $a=18.115(17) \AA$,

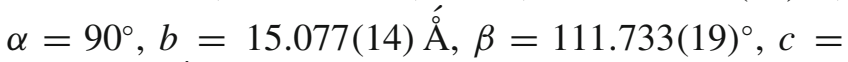
11.084(10) $\AA, \gamma=90^{\circ}, V=812(5) \AA^{3}, Z=4, D_{\text {calc. }}=$ $1.288 \mathrm{Mg} / \mathrm{m}^{3}$, and the final $R$ factor was $R_{1}=0.065$, 4242 reflections were observed with $I_{0}>2 \sigma\left(I_{0}\right), \mathrm{R}_{\omega}=$ 0.1674 for all data. The structure was solved by full-matrix least-squares on $F^{2}$ using the SHELXTL PROGRAM. ${ }^{11}$

\subsection{Preparation of complexes}

2.2a Complex 1: $0.5010 \mathrm{~g}$ (4.20 mmol) 5-amino-2cyanopyridines and $40 \mathrm{~mL}$ anhydrous ethanol were dispersed in a $100 \mathrm{~mL}$ round bottom flask. Then, $1.4346 \mathrm{~g}$ ( $8.40 \mathrm{mmol}) \mathrm{CuCl}_{2} \cdot 2 \mathrm{H}_{2} \mathrm{O}$ was added into the above solution. The mixture was refluxed for $48 \mathrm{~h}\left(80-90^{\circ} \mathrm{C}\right)$. After hot filtration, residue was obtained. Recrystallization with anhydrous methanol afforded blue crystals. Yield: $42 \%$. M.p.: $158-162^{\circ} \mathrm{C}$ Elemental analysis: Anal. Calc. for $\mathrm{C}_{9} \mathrm{H}_{17} \mathrm{Cl}_{2} \mathrm{CuN}_{3} \mathrm{O}_{3}: \mathrm{C}, 30.09 ; \mathrm{H}, 4.86 ; \mathrm{N}$, 12.00\%; Found: C, 31.39; H, 4.39; N, 12.42\%.IR (KBr, pellet, $v / \mathrm{cm}^{-1}$ ): $3425,3324,3218,1634,1590,1470$, 1423, 1390, 1311, 1289, 1147, 1014, 883, 853, 677, $528,491$.

2.2b Complex 2: $0.5962 \mathrm{~g}$ (5.0 mmol) 5-amino-2cyanopyridines and $40 \mathrm{~mL}$ anhydrous ethanol were

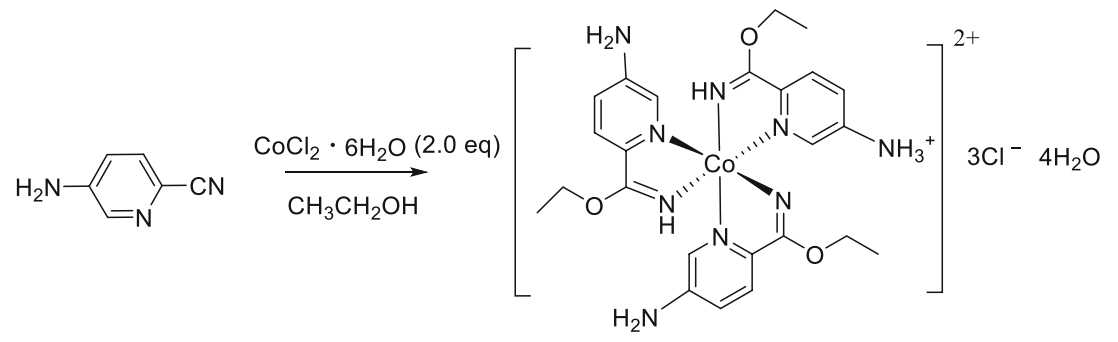

Scheme 2. The synthetic route for complex 2. Reagents and conditions: ethanol, $80-90^{\circ} \mathrm{C}, 48 \mathrm{~h}$.
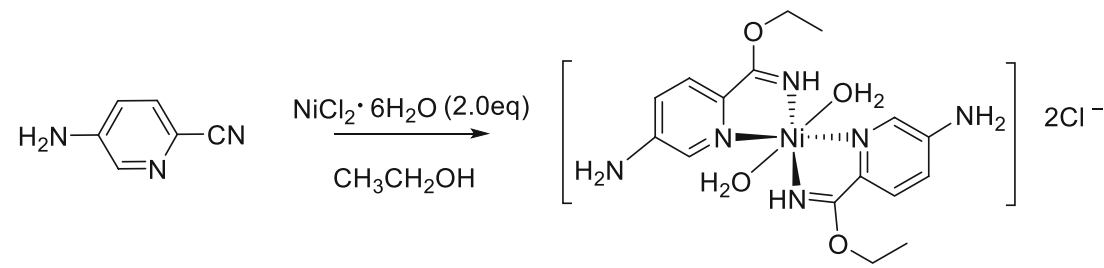

Scheme 3. The synthetic route for complex 3. Reagents and conditions: ethanol, $80-90^{\circ} \mathrm{C}, 48 \mathrm{~h}$. 


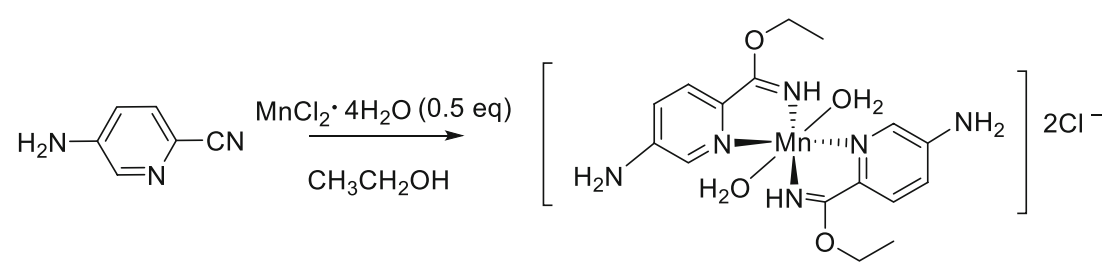

Scheme 4. The synthetic route for complex 4. Reagents and conditions: ethanol, $80-90^{\circ} \mathrm{C}, 48 \mathrm{~h}$.

dispersed in a $100 \mathrm{~mL}$ round bottom flask, then $2.3798 \mathrm{~g}$ (10.0 mmol) $\mathrm{CoCl}_{2} \cdot 6 \mathrm{H}_{2} \mathrm{O}$ was added into the above solution. The mixture was refluxed for $48 \mathrm{~h}\left(80-90^{\circ} \mathrm{C}\right)$. After hot filtration, the solution was evaporated slowly in the air, to afford the solid. Recrystallization with anhydrous methanol yielded purple red crystals. Yield: 32\%. M.p.: $>200^{\circ} \mathrm{C}$ Elemental analysis: Anal. Calc. for $\mathrm{C}_{24} \mathrm{H}_{40} \mathrm{Cl}_{3} \mathrm{CoN}_{9} \mathrm{O}_{7}$ : C, 39.34; $\mathrm{H}, 5.46 ; \mathrm{N}, 17.21 \%$; Found: C, 39.33; H, 5.17; N, 17.16\%. IR (KBr pellet, $\left.v / \mathrm{cm}^{-1}\right)$ : 3288, 2911, 1616, 1592, 1429, 1326, 1235, $1182,1001,899,857,682,587,489,459$.

2.2c Complex 3: $0.5020 \mathrm{~g}(4.2 \mathrm{mmol})$ 5-amino-2cyanopyridines and $40 \mathrm{~mL}$ anhydrous ethanol were dispersed in a $100 \mathrm{~mL}$ round flask, then $1.9984 \mathrm{~g}$ ( $8.4 \mathrm{mmol}) \mathrm{NiCl}_{2} \cdot 6 \mathrm{H}_{2} \mathrm{O}$ was added into the above solution. The mixture was refluxed for $48 \mathrm{~h}\left(80-90^{\circ} \mathrm{C}\right)$. After hot filtration, solution was evaporated slowly in the air, and light green crystals appeared. Yield: $15 \%$. M.p.: $>200^{\circ}$ C. Elemental analysis: Anal. Calc. for $\mathrm{C} 16 \mathrm{H} 26 \mathrm{Cl} 2 \mathrm{NiN} 6 \mathrm{O} 4$ : C, 38.74; $\mathrm{H}, 5.24 ; \mathrm{N}, 16.93 \%$; Found: C, 38.55; H, 5.41; N, 16.54\%. IR (KBr pellet, $\left.v / \mathrm{cm}^{-1}\right): 3306,3201,1634,1593,15691470,1420$, $1385,1363,1310,1287,1206,1162,1045,1018,848$, $817,772,672,633,536,487$.

2.2d Complex 4: $1.1990 \mathrm{~g}$ (10.0 mmol) 5-amino-2cyanopyridines and $40 \mathrm{~mL}$ anhydrous ethanol were dispersed in a $100 \mathrm{~mL}$ round flask, then $0.9817 \mathrm{~g}$ (5.0 mmol) $\mathrm{CoCl}_{2} \cdot 4 \mathrm{H}_{2} \mathrm{O}$ was added into the above solution. The mixture was refluxed for $48 \mathrm{~h}$ (80$90^{\circ} \mathrm{C}$ ). After hot filtration, solution was evaporated slowly in the air, and yellow crystals appeared. Yield: 35\%. M.p.:150-154 ${ }^{\circ}$ C. Elemental analysis: Anal. Calc. C16H26Cl2MnN6O4: C, 39.04; H, 5.32; N, 17.07\%; Found: C, 39.56; H, 5.53; N, 16.93\%; IR (KBr pellet, $\left.v / \mathrm{cm}^{-1}\right): 3297,3186,2985,2319,1632,1589,1568$, 1504, 1474, 1384, 1304, 1286, 1199, 1158, 1107, 1014, 904, 849, 806, 704, 666, 657, 624, 572, 529, 515, 462.

\subsection{The Henry reaction catalyzed by complexes}

Catalyst $(0.075 \mathrm{mmol})$ was dissolved in $1 \mathrm{~mL} \mathrm{CH}_{3} \mathrm{OH}$, $0.05 \mathrm{~mL}$ benzaldehyde $(0.5 \mathrm{mmol})$ and $0.25 \mathrm{~mL}$
( $5 \mathrm{mmol})$ nitromethane were added to the methanol solution in a dry $25 \mathrm{~mL}$ Schlenk flask. The reaction mixture was stirred vigorously for $24 \mathrm{~h}$ at room temperate and then was analyzed by ${ }^{1} \mathrm{H}$ NMR.

\section{Results and Discussion}

\subsection{Synthesis and structures}

The use of 5-amino-2-cyanopyridine with 2.0 equiv of $\mathrm{CuCl}_{2} \cdot \mathrm{H}_{2} \mathrm{O}$ or $\mathrm{CoCl}_{2} \cdot 6 \mathrm{H}_{2} \mathrm{O}$ or $\mathrm{NiCl}_{2} \cdot 6 \mathrm{H}_{2} \mathrm{O}$ in ethanol first resulted in the formation of 5-amino 2ethylpyridine-2-carboximidate as the intermediate; the 1:1 adduct with $\mathrm{CuCl}_{2}, 1: 3$ adduct with $\mathrm{CoCl}_{2}$, and 1:2 adduct with $\mathrm{NiCl}_{2}$ were then obtained unexpectedly. In

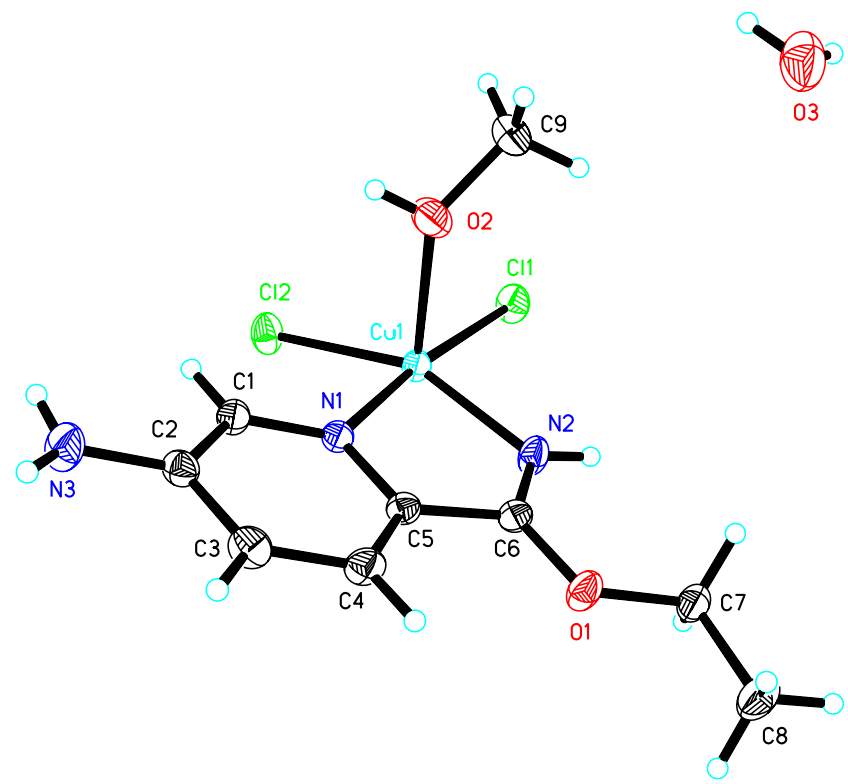

Figure 1. ORTEP diagram of complex 1 (30\% probability thermal ellipsoids). Selected bond lengths (尺́) and angles (deg): $\mathrm{Cu}(1)-\mathrm{N}(2)$ 1.960(2), $\mathrm{Cu}(1)-\mathrm{N}(1)$ 2.0412(18), Cu(1)$\mathrm{O}(2)$ 2.2542(18), $\mathrm{Cu}(1)-\mathrm{Cl}(2) 2.2587(6), \mathrm{Cu}(1)-\mathrm{Cl}(1) 2.2833$ (7), $\mathrm{N}(2)-\mathrm{Cu}(1)-\mathrm{N}(1)$ 80.05(8), N(2)-Cu(1)-O(2) 100.26(9), $\mathrm{N}(1)-\mathrm{Cu}(1)-\mathrm{O}(2) 84.29(7), \mathrm{N}(2)-\mathrm{Cu}(1)-\mathrm{Cl}(2)$ 155.86(7), N(1)$\mathrm{Cu}(1)-\mathrm{Cl}(2)$ 92.31(5), O(2)-Cu(1)-Cl(2) 101.73(6), N(2)$\mathrm{Cu}(1)-\mathrm{Cl}(1)$ 93.15(6), N(1)-Cu(1)-Cl(1)173.17(5), O(2)-Cu (1)-Cl(1)96.48(6), Cl(2)-Cu(1)-Cl(1) 94.17(2), C(1)-N(1)$\mathrm{Cu}(1)$ 127.42(15), C(5)-N(1)-Cu(1)112.97(14), C(6)-N(2)$\mathrm{Cu}(1) 116.38(16), \mathrm{Cu}(1)-\mathrm{N}(2)-\mathrm{H}(2) 122.6(19)$. 
contrast, the synthesis of complex 4 was carried out in anhydrous ethanol using a molar ratio of 2:1 of 5amino-2-cyanopyridine to $\mathrm{MnCl}_{2} \cdot 4 \mathrm{H}_{2} \mathrm{O}$; since no crystals appeared for the ligand to $\mathrm{MnCl}_{2} \cdot 4 \mathrm{H}_{2} \mathrm{O}$ for molar ratio of 1:2, we adopted a molar ratio of 2:1 instead of $1: 2$, which then afforded the yellow crystals of complex 4 after slow evaporation in air.

All the reactions were refluxed for $48 \mathrm{~h}$. The crystal structures of the green complex 1 and purple red complex 2 were obtained after recrystallization in methanol, whereas the light green crystals of complex $\mathbf{3}$ were formed by slow evaporation of the filtrate of the ethanol solvent. It is noteworthy that in this reaction, the range of $\mathrm{pH}$ value are all between $7-8$, which are weakly alkaline.

The synthetic routes for the above mentioned four complexes 1-4 can be summarized as follows (schemes 1-4, figures 1-4).

The formation of complexes 1-4 occurs through an intermediate of the functionalized $\mathrm{CH}_{3} \mathrm{CH}_{2} \mathrm{OC}=\mathrm{NH}$ group obtained from ethanol by the attack of the cyano group by the nucleophilic reagents. The complexes were all easily soluble in methanol and ethanol and dissolved with difficulty in n-hexane, petroleum ether and ether.

It is important to note that one $\mathrm{HCl}$ molecule was produced in the synthesis of complex 2. Ammonium salts were formed with one of the amino groups of the tridentate ligands. In complex 2, Co(III) may be obtained by air oxidation of $\mathrm{Co}$ (II) complex. And we have proved this conjecture carrying this work under anaerobic condition $\left(\mathrm{N}_{2}\right)$ isolating $\mathrm{Co}$ (II) complex which could be oxidized by $\mathrm{H}_{2} \mathrm{O}_{2}$ to $\mathrm{Co}$ (III) complex, 2 .

The structures of complexes 1-4 were determined by $\mathrm{X}$-ray diffraction.

Complex $\mathbf{1}$ is a $\mathrm{Cu}-\mathrm{N}$ complex with a free $\mathrm{H}_{2} \mathrm{O}$ molecule. $\mathrm{Cu}$ (II) is five-coordinated with square geometry, the coordination sphere composed of two $\mathrm{N}$ atoms from a chelating 5-amino-O-ethyl pyridine-2carboximidate ligand, one methanol molecule, and two chloride atoms. The bond length of $\mathrm{Cu}(1)-\mathrm{N}(1)[2.0412$

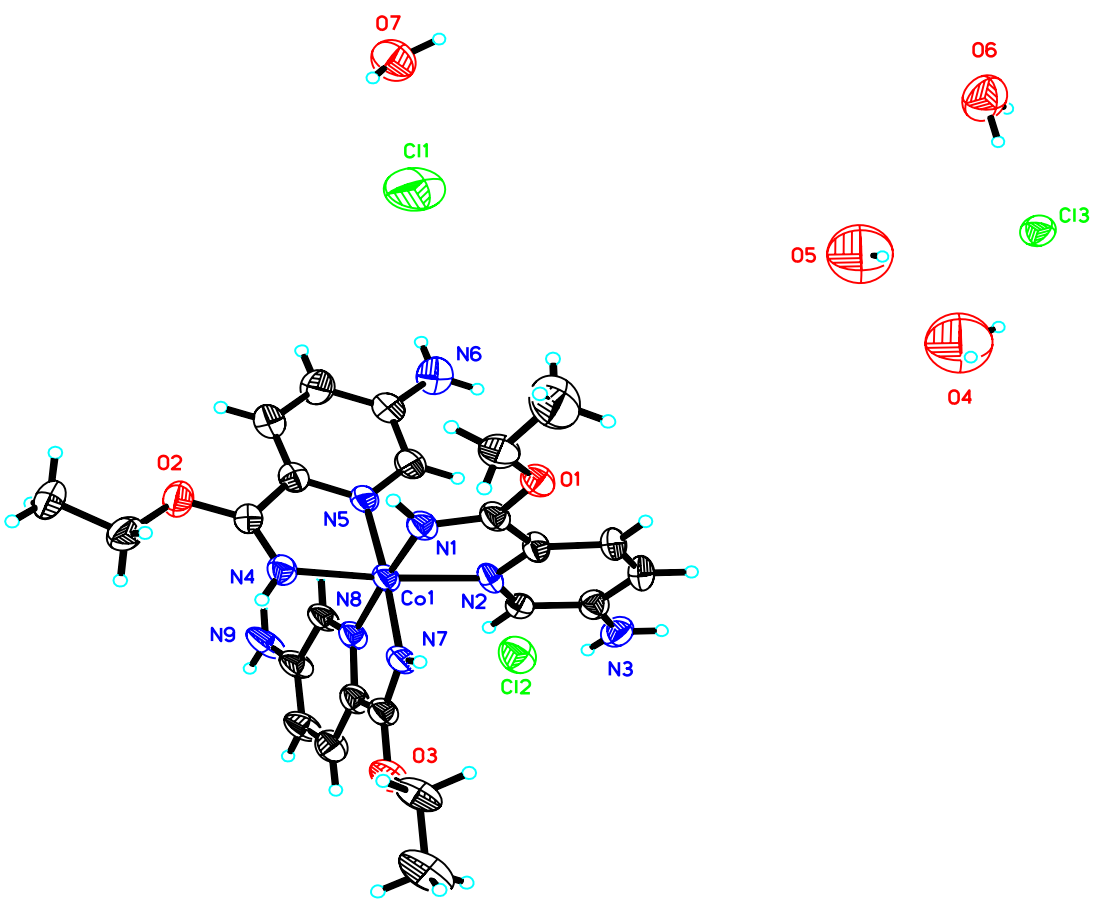

Figure 2. ORTEP diagram of complex 2 (30\% probability thermal ellipsoids). Selected bond lengths (̊̊) and angles (deg): $\operatorname{Co}(1)-\mathrm{N}(7)$ 1.893(5), $\mathrm{Co}(1)-\mathrm{N}(1)$ 1.910(5), $\mathrm{Co}(1)-\mathrm{N}(4)$ 1.918(6), Co(1)-N(5) 1.931(6), Co(1)-N(2) 1.933(5), $\mathrm{Co}(1)-\mathrm{N}(8)$ 1.940(5), N(7)-Co(1)-N(1) 92.5(2), N(7)-Co(1)-N(4) 93.2(3), N(1)-Co(1)-N(4) 92.4(2), N(7)-Co(1)-N(5) 176.3(2), N(1)-Co(1)-N(5) 89.1(2), N(4)-Co(1)-N(5) 83.4(2), N(7)-Co(1)-N(2) 89.1(2), N(1)-Co(1)-N(2) 83.1(2), N(4)-Co(1)-N(2)175.80(2), N(5)-Co(1)-N(2)94.4(2), N(7)-Co(1)-N(8) $82.8(2), \mathrm{N}(1)-\mathrm{Co}(1)-\mathrm{N}(8)$ 175.3(2), N(4)-Co(1)-N(8) 88.1(2), N(5)-Co(1)-N(8) 95.6(2), N(2)-Co(1)-N(8) 96.6(2), C(1)-N(1)-Co(1) 114.7(5), C(2)-N(2)-Co(1) 112.6(5), C(9)-N(4)-Co(1) 113.7(5), C(10)-N(5)-Co(1) 113.14(4), C(14)$\mathrm{N}(5)-\mathrm{Co}(1)$ 128.3(5), C(17)-N(7)-Co(1) 115.7(4), C(22)-N(8)-Co(1) 126.4(5), $\mathrm{C}(18)-\mathrm{N}(8)-\mathrm{Co}(1) 112.6(4)$. 


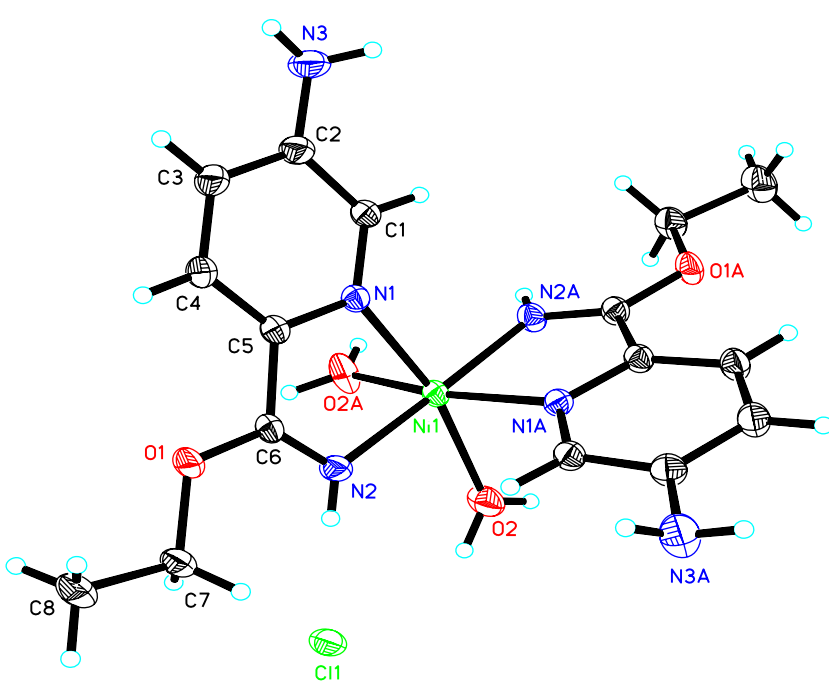

Figure 3. ORTEP diagram of complex 3 (30\% probability thermal ellipsoids). Selected bond lengths (§̊) and angles (deg): Ni(1)-O(2) 2.0925(17), Ni(1)-O(2)\#1 2.0925(17), $\mathrm{Ni}(1)-\mathrm{N}(1)$ 2.0902(18), Ni(1)-N(2)\#1 2.040(2), Ni(1)-N(2) 2.040(2), O(2)\#1-Ni(1)-O(2) 90.38 (11), N(1)\#1-Ni(1)-O(2) 87.72(8), N(1)-Ni(1)-O(2) 167.09(6), N(1)\#1-Ni(1)-O(2)\#1 167.09(6), N(1)-Ni(1)-O(2)\#1 87.72(8), N(1)-Ni(1)-N(1)\#1 96.89(10), N(2)\#1-Ni(1)-O(2)\#1 88.86(7), N(2)\#1-Ni(1)$\mathrm{O}(2)$ 94.83(8), N(2)-Ni(1)-O(2) 88.86(7), N(2)-Ni(1)-O(2)\#1 94.83(8), N(2)-Ni(1)-N(1)\#1 97.90(8), N(2)\#1-Ni(1)-N(1) 97.90(8), N(2)\#1-Ni(1)-N(1)\#1 78.58(7), N(2)-Ni(1)-N(1) 78.58(7), $\quad$ C(1)-N(1)-Ni(1) 126.86(15), $\quad$ C(5)-N(1)-Ni(1) 113.54(14), C(6)-N(2)-Ni(1) 116.26(15).

(18) $\AA$ ] is longer than the bond length of $\mathrm{Cu}(1)-\mathrm{N}(2)$ [1.960 (2) $\AA$ ], which are consistent with the values previously reported for five coordinated mononuclear $\mathrm{Cu}$ complex such as Dichloro(O-ethyl 3-methylpyridine2-carboximidic acid- $\left.\mathrm{k}^{2} \mathrm{~N}, \mathrm{~N}^{\prime}\right)$ copper(II). ${ }^{12}$ The crystal structure of complex $\mathbf{1}$ is stabilized by numerous hydrogen bonds of $\mathrm{O}-\mathrm{H} \cdot \mathrm{Cl}, \mathrm{N}-\mathrm{H} \cdots \mathrm{Cl}, \mathrm{O}-\mathrm{H} \cdots \mathrm{O}$, and $\mathrm{N}-\mathrm{H}^{\cdots} \mathrm{O}$.

Complex 2 is a Co-N complex. The central cobalt ion $\left(\mathrm{Co}^{2+}\right)$ shows a nearly octahedral six-fold coordination and is surrounded by three $\mathrm{N}$ (pyridine) atoms and by three (imino ether group) donor atoms in the facial configuration. The complex consists of $\left[\mathrm{Co}(\mathrm{EtPy})_{3}\right]^{2+}$ cations, $\mathrm{Cl}^{-}$counter-anions and two $\mathrm{H}_{2} \mathrm{O}$ molecules. EtPy is an $\mathrm{N}$, N-coordinated bidentate ligand. The Co-N bond lengths range from 1.893 (5) $\AA$ to 1.940 (5) $\AA$, which are in agreement with the literature without unusual features. ${ }^{10}$ The N(7)-Co(1)-N(8) and N(4)$\mathrm{Co}(1)-\mathrm{N}(2)$ angles were $82.8(2)^{\circ}$ and $175.8(2)^{\circ}$, respectively, and other $\mathrm{N}-\mathrm{Co}(1)-\mathrm{N}$ angles were in the range, $83.1(2)^{\circ}-175.3(2)^{\circ}$.

The crystal structures of complexes $\mathbf{3}$ and $\mathbf{4}$ are similar, with both showing a symmetric structure and sixfold coordination consisting of $\left[\mathrm{Ni}(5 \text {-amino-EtPy })_{2}\right]^{2-}$ cations or $\left[\mathrm{Mn}(5 \text {-amino-EtPy })_{2}\right]^{2-}$ cations, $\mathrm{Cl}^{-}$counter

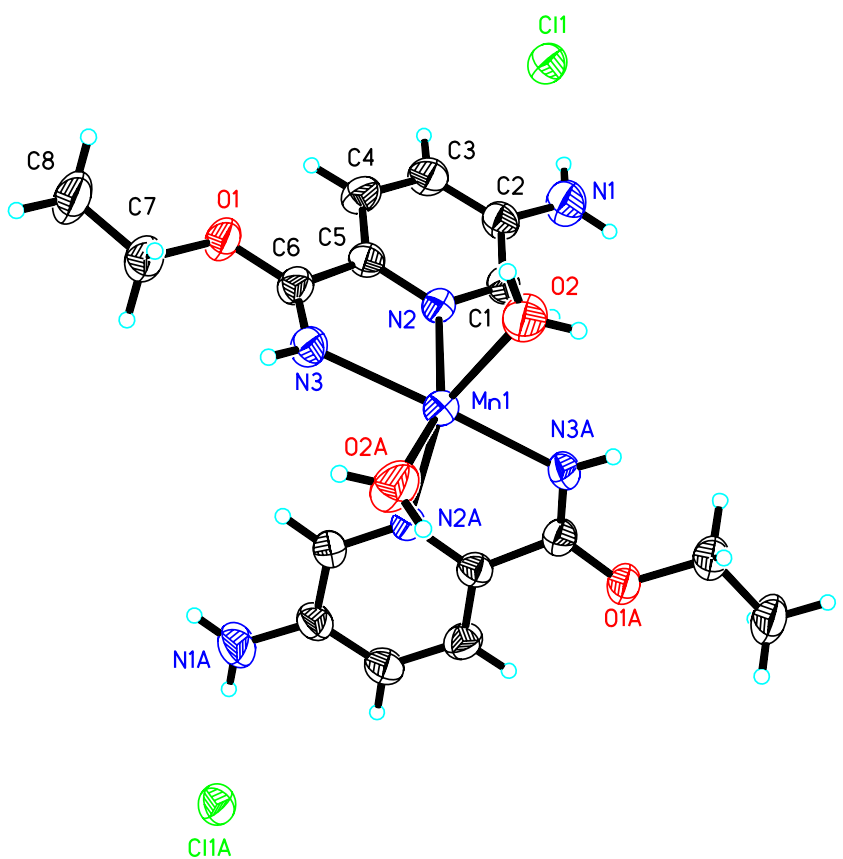

Figure 4. ORTEP diagram of complex 4 (30\% probability thermal ellipsoids). Selected bond lengths (Á) and angles (deg): $\mathrm{Mn}(1)-\mathrm{O}(2)$ 2.167(4), $\mathrm{Mn}(1)-\mathrm{O}(2) \# 1$ 2.167(4), Mn(1)$\mathrm{N}(3) \# 1$ 2.191(5), Mn(1)-N(3) 2.191(5), Mn(1)-N(2)\#1 2.282 (4), $\mathrm{Mn}(1)-\mathrm{N}(2)$ 2.282(4), O(2)-Mn(1)-O(2)\#1 92.3(2), O (2)-Mn(1)-N(3)\#1 86.43(17), O(2)\#1-Mn(1)-N(3)\#1 104.66 (16), O(2)-Mn(1)-N(3) 104.66(16), O(2)\#1-Mn(1)-N(3) 86.42 (17), N(3)\#1-Mn(1)-N(3) 164.2(3), O(2)-Mn(1)-N(2)\#1 157.98(14), O(2)\#1-Mn(1)-N(2)\#1 89.18(16), N(3)\#1-Mn (1)-N(2)\#1 71.98(17), N(3)-Mn(1)-N(2)\#1 97.36(16), O(2)$\mathrm{Mn}(1)-\mathrm{N}(2) \quad 89.17(16), \quad \mathrm{O}(2) \# 1-\mathrm{Mn}(1)-\mathrm{N}(2) \quad 157.98(14)$, $\mathrm{N}(3) \# 1-\mathrm{Mn}(1)-\mathrm{N}(2)$ 97.36(16), N(3)-Mn(1)-N(2) 71.98(17), $\mathrm{N}(2) \# 1-\mathrm{Mn}(1)-\mathrm{N}(2)$ 97.62(19), C(1)-N(2)-Mn(1) 125.5(3), C(5)-N(2)-Mn(1) 115.2(3), C(6)-N(3)-Mn(1) 119.7(4).

anions and two $\mathrm{H}_{2} \mathrm{O}$ molecules. All atoms are in the same general positions. The nitrogen atom is surrounded by two $\mathrm{O}$ atoms $\left(\mathrm{H}_{2} \mathrm{O}\right.$ molecules $)$ and by four $\mathrm{N}$ (5-amino-2-cyanopyridine) atoms. The $\mathrm{Ni}(1)-\mathrm{O}(2)$, $\mathrm{Ni}(1)-\mathrm{N}(1)$ and $\mathrm{Ni}(1)-\mathrm{N}(2)$ bond lengths are 2.0925(17), 2.0902 (18) $\AA$, and 2.040 (2) $\AA$, respectively. The N(1)$\mathrm{Ni}(1)-\mathrm{O}(2), \mathrm{N}(2)-\mathrm{Ni}(1)-\mathrm{O}(2), \mathrm{N}(2)-\mathrm{Ni}(1)-\mathrm{N}(1)$ bond angles are $167.09(6)^{\circ}, 88.86(7)^{\circ}$, and $78.58(7)^{\circ}$, respectively. The Mn-N bond lengths range from 2.1915 (5) $\AA$ to 2.282 (5) $\AA$. Both the Mn-N and Ni-N are in agreement with those reported for $\mathrm{Di}-\mu$-acetato-bis (dimethylformamide)pentakis( $\mu-\mathrm{N}, 2$-dioxidobenzene1-carboximidato)tetrakis(1-ethylimidazole)pentamanganese(III)manganese(II)-diethylether-dimethylforamide -methanol-water ${ }^{13,14}$ and [Ni(O-methylpyridine-2-carboximidate) $\left.)_{3}\right] \mathrm{Br}_{2} \cdot 4 \mathrm{H}_{2} \mathrm{O} .{ }^{10}$

These structural parameters are all typical. Such values are usually found for the combinations of such free molecules with complexes formed by hydrogen bonds. 


\subsection{Henry Reactions}

Henry reaction (table 1) was catalyzed by $15 \mathrm{~mol} \%$ of the four complexes 1-4 without any additives in methanol. The catalytic activities are shown in table 1 .

Inspection of the data in table 1 shows that the conversion efficiency of these complexes were higher than 55\%. Further optimization reactions were explored at room temperature with lower catalyst loadings of $10 \mathrm{~mol} \%$ and $5 \mathrm{~mol} \%$. We were delighted to observe that the complexes 1-4 in methanol at room temperature afforded the corresponding nitroalcohol with $10 \mathrm{~mol} \%$ after $24 \mathrm{~h}$ in $74 \%, 68 \%, 78 \%$, respectively, and $42 \%$, but afforded the corresponding nitroalcohol in $17 \%, 66 \%$, $68 \%$ and $29 \%$ when the catalyst loading is reduced to $5 \mathrm{~mol} \%$ (table 2).

We also did a parallel experiment without the catalysts, and the conversion efficiency was only $26 \%$. It is much lower than that of the Henry reaction with complexes as catalysts.

From the tables 1 and 2, we can conclude that all complexes were effective catalysts for the Henry

Table 1. Catalytic activity of the four complexes to the Henry reaction. ${ }^{\mathrm{a}}$

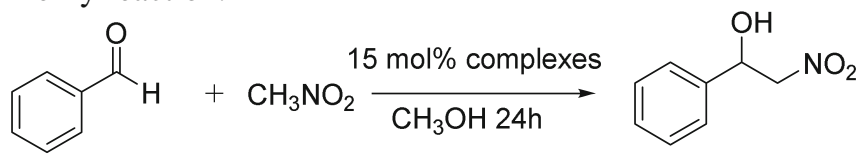

\begin{tabular}{lc}
\hline Complex & Conversion $(\%)^{\mathrm{b}}$ \\
\hline $\mathbf{1}$ & 67 \\
$\mathbf{2}$ & 83 \\
$\mathbf{3}$ & 87 \\
$\mathbf{4}$ & 55 \\
no catalysts & 26 \\
\hline
\end{tabular}

${ }^{\mathrm{a}}$ Reactions were carried out with $0.5 \mathrm{mmol} \mathrm{PhCHO}$ and $0.25 \mathrm{~mL} \mathrm{CH}_{3} \mathrm{NO}_{2}$ in $1 \mathrm{~mL} \mathrm{CH} \mathrm{CH}_{3} \mathrm{OH}$ using $15 \mathrm{~mol} \%$ of catalyst at room temperature $\left(10-20^{\circ} \mathrm{C}\right) .{ }^{\mathrm{b}} \mathrm{Conv} . \%$ was determined by ${ }^{1} \mathrm{H}$ NMR.

Table 2. Effect of the catalysts loading to the Henry reaction. ${ }^{\text {a }}$

\begin{tabular}{lll}
\hline Complex & Conversion $(\%)^{\mathrm{b}, \mathrm{c}}$ & Conversion $(\%)^{\mathrm{b}, \mathrm{d}}$ \\
\hline $\mathbf{1}$ & 74 & 17 \\
$\mathbf{2}$ & 68 & 66 \\
$\mathbf{3}$ & 78 & 68 \\
$\mathbf{4}$ & 42 & 29 \\
\hline
\end{tabular}

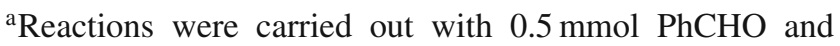
$0.25 \mathrm{~mL} \mathrm{CH} \mathrm{CH}_{3} \mathrm{NO}_{2}$ in $1 \mathrm{~mL} \mathrm{CH}_{3} \mathrm{OH}$ using $10 \mathrm{~mol} \%$ of catalyst at room temperature $\left(10-20^{\circ} \mathrm{C}\right) .{ }^{\mathrm{b}}$ Conversion $\%$ was determined by ${ }^{1} \mathrm{H}$ NMR. ${ }^{\mathrm{c}} 10 \mathrm{~mol} \%$ catalyst loading. ${ }^{\mathrm{d}} 5 \mathrm{~mol} \%$ catalyst loading. reaction, and complex $3(15 \mathrm{~mol} \%)$ was found to be the best choice for this reaction, giving $87 \%$ conversion.

The following catalytic reaction mechanism can be proposed: the complexes first strongly activate the $\mathrm{C}=\mathrm{O}$ bond, which is followed by nucleophilic addition reaction of $\mathrm{CH}_{2} \mathrm{NO}_{2}^{-}$onto the carbonyl group.

\section{Conclusions}

In conclusion, the crystal structures of four metal complexes involving 5-amino-2-ethylpyridine-2-carboximidate have been reported for the first time. The complexes were synthesized using a simple method. The obtained complexes were shown to be good catalysts for the Henry reaction. Further study of these complexes in other organic reactions such as cyanosilylation and hydroboration reactions is currently ongoing.

\section{Supplementary Information (SI)}

Crystallographic information for all the compounds have been deposited with the Cambridge crystallographic data center, (CCDC) as supplementary publications CCDC 1455248, 1455249, 1455251 and 1455252. The electronic Supplementary Information is available at www.ias.ac.in/chemsci.

\section{Acknowledgments}

This work was supported by Hefei University of Technology.

\section{References}

1. Bloch R 1998 Chem. Rev. 981407

2. Kobayashi S and Ishitani S H 1999 Chem. Rev. 991069

3. Friestad G K 2001 Tetrahedron 575461

4. Galt R H B, Hitchcock P B, Mccarthy S J and Young D W 1996 Tetrahedron Lett. 378035

5. Folgado J V, Coronado E, Beltrán-Porter D R, Burriel R A, Fuertes A and Miravitlle C S 1988 J. Chem. Soc. Dalton 123041

6. Alekha K S, Tungabidya M, Yasobanta D and Prasanta R 2014 J. Chem. Sci. 1261695

7. Harinath Y, Subba R D, Suresh D and Seshaiah K 2016 J. Chem. Sci. 12843

8. Lee D W, Seo E Y, Cho S I and Yi C S 2004 J. Polym. Sci. Pol. Chem. 422747

9. Doyle M, Phillips L M and Hu W H 2001 J. Am. Chem. Soc. 1235366

10. Jamnický M, Segl'a P and Koman M 1995 Polyhedron 141837

11. Sheldrick G M SHELXS-97 1997 In Program for $X$-ray Crystal Structure Solution (Göttingen University: Gottingen, Germany)

12. Xuan R C, Xu M and Cheng D P 2006 Acta Cryst. C 62587

13. Segla P and Jamnicky M 1988 Inorg. Chim. Acta 14693

14. Travis J R, Matthias Z and Zaleskia C M 2015 Acta Cryst. E 71130 